\title{
Increase of energy efficiency in proportional adjusting of flow rate in the boiler circuit
}

\author{
Pavel A. Artamonov ${ }^{1, *}$, Nikolai I. Kurilenko ${ }^{1}$, and Gennady Ya. Mamontov ${ }^{2}$ \\ ${ }^{1}$ Tyumen Industrial University, 625000 Tyumen, Russia \\ ${ }^{2}$ National Research Tomsk Polytechnic University, 634050 Tomsk, Russia
}

\begin{abstract}
The article presents the results of theoretical studies in the field of the boiler circuit operating modes for the boiler rooms operating by the independent heat supply scheme. The 3D model of a boiler circuit for a boiler room with $3 \mathrm{MW}$ rated output was developed, based on which there was made an estimation of the boiler pump performance indicators. There is proposed a method for reducing energy costs for the operation of the pumping equipment of the boiler circuit.
\end{abstract}

\section{Introduction}

The strong policy in the field of increasing energy efficiency in the world as well as in Russia has led to the strict requirements for energy facilities. The major priority is not the volume increase of the energy complex production, but the modernization of the country's energy sector [1]. At the same time over the past few years there has been an increase in the number of individual boiler rooms [2]. The reason for it is the studies devoted to assessing the positive effect of the decentralization of the heat supply systems (such as [3], [4], etc.). While the number of boiler rooms is increasing and the cost of energy resources is going up the development of ways to increase the heat production efficiency is an urgent task of theoretical and practical research.

\section{Problem statement and solution methods}

This article presents the result of an analytical evaluation of the effectiveness of the control method which is based on a change of the flow rate in the boiler circuit in proportion to the heat load of consumers connected through an independent heat supply scheme.

Generally the release of heat energy in the boiler circuit can be changed by adjusting the combustion parameters (flame modulation), by changing the temperature and flow rate of the heat transfer fluid. Consider the basic scheme of the boiler house, presented in Figure 1.

\footnotetext{
* Corresponding author: P.Artamonovv@yandex.ru
} 


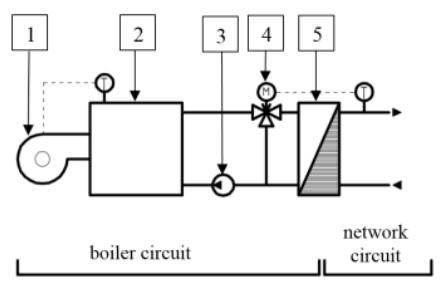

Fig.1. The schematic diagram of the boiler circuit operation.

The circulation of the heat transfer fluid through the boiler (pos. 2) and heat exchanger (pos. 5) is carried out by the boiler pump (pos. 3), and the amount of the heat supplied to the consumer and the temperature control of the network circuit according to the temperature chart is carried out by the three-way valve (pos. 4). This scheme of the boiler room operation is generally used during design and construction. The activation of the boiler pump (pos. 3) occurs when the burner starts (pos. 1). At the same time regardless of the capacity of the burner, the total flow of the heat transfer fluid through the boiler remains conditionally constant because the pump operates at a constant speed of the impeller as determined by the design of the electric motor. The flow deviation can be caused only by the displacement of the operating point according to the pump characteristic as a result of the change in the hydraulic resistance in the boiler circuit (changing the position of the three-way valve, deposits in the pipelines, shutting off the stop valves, etc.) [5]. The considered operation principle of the boiler pump is simple and reliable for the automation of the technological cycle. However, this solution is not optimal for the energy efficiency. In order to evaluate the efficiency indicators consider the boiler circuit assemble model designed according to the scheme in Figure 1 (Figure 2).

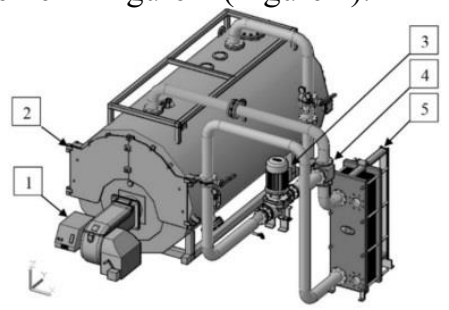

Fig.2. The model of the boiler circuit assemble.

The designation of the equipment corresponds to the numbering shown in Figure 1. The power (Q) of the considered circuit is $3 \mathrm{MW}$ (boiler model KSV-3.0 manufactured by MAXTERM (pos.2)). The calculated temperature difference at the boiler inlet and outlet is $25 \mathrm{oC}$. The temperature at the boiler outlet is $105{ }^{\circ} \mathrm{C}$. The heat carrier is water with a heat capacity of $4.208 \mathrm{~kJ} / \mathrm{kg} \cdot{ }^{0} \mathrm{C}$ and a dynamic viscosity of $0.3078 \cdot 10^{-3} \mathrm{~Pa} . \mathrm{s}$ at an average temperature. The calculated flow rate of the heat carrier under the given conditions is 102.7 $\mathrm{m}^{3} / \mathrm{h}$. There were used a heat exchanger NN-62-16 / 2-78-TKTM40 (pos. 5) manufactured by Ridan and a three-way valve DR150GFLA (pos. 4) manufactured by Honeywell. Rotary shutters were used as shut-off valves. In order to select the pump (pos. 3 ) the calculation of the pressure loss was made considering all local resistances and equipment characteristics. When modeling the hydraulic mode the pressure loss due to friction by the length was determined by the Darcy-Weisbach equation, the losses in local resistances were determined by the Weisbach equation. The losses on the equipment (dampers, return and three-way valves, air collectors, etc.) were determined by the capacity factor specified in the manufacturer's technical documentation. The estimated hydraulic losses during the operation on the rated power mode amounted to $7.4 \mathrm{~mm} \mathrm{H}_{2} \mathrm{O}$. The unit was equipped with the pump IL100/170-3/4 manufactured by Wilo with the following characteristics at the 
operating point: consumption $-105.5 \mathrm{~m}^{3} / \mathrm{h}$, pressure $-7.76 \mathrm{~m}^{3} / \mathrm{h}$, energy consumption $3.15 \mathrm{~kW}$.

\section{Results and discussion}

As noted earlier, while regulating the amount of heat given out to the consumer using the three-way valve (pos. 4), the total hydraulic resistance of the system changes and the operating point of the pump shifts. In order to assess the effect of heat consumption on the electric power of the pump we will calculate the operating parameters of the boiler circuit model when the heat load of consumers varies from $300 \mathrm{~kW}$ to $3000 \mathrm{~kW}$ in $300 \mathrm{~kW}$ steps. The value of the electric power consumption of the boiler pump (P1) depending on the heat load of the consumers, expressed as a percentage of the installed heat output (Q), is shown on Figure 3 (dotted line).

The results of the calculation show that the consumed electric power of the pump varies from $3.35 \mathrm{~kW}$ to $3.15 \mathrm{~kW}$ when the heating power of the circuit varies from $10 \%$ to $100 \%$. The reduce of energy consumption occurs due to the displacement of the operating point because of the change in the hydraulic resistance when the three-way valve is adjusted (pos. 4). Let us consider the relation between the generated power output (Q), the electric power consumption of the pump (P1) and the heat load expressed in percentage (Figure 4, dotted line).

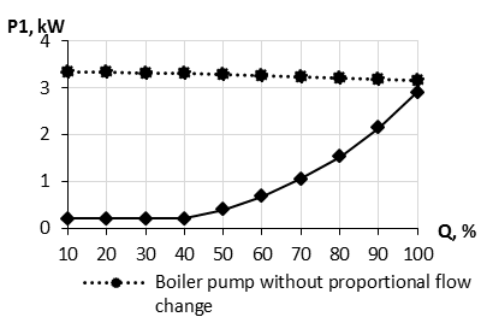

Fig.3. Consumed electrical power of the boiler pump, depending on the heat load of consumers.

It is obvious from the presented dependence that when the heat load decreases this ratio decreases as well. Therefore more electricity is consumed to produce each one megawatt of heat which means that the operating costs of the boiler room are increasing. The system reaches the most efficiency when operating at nominal heat output (at $100 \%$ ). However, the graph of consumption of heat energy has a curvilinear characteristic during the year and the concept of peak loads is normatively established. Analyzing this graph under various climatic conditions it can be concluded that most of the time the boiler room does not work at the nominal power. Thus, when the heat load decreases the technical solution with the installation of a boiler pump operating at a constant engine speed becomes inefficient.

To improve the energy efficiency of the boiler circuit it seems reasonable to change the performance of the pump, particularly the adjusting the flow rate of the pump in proportion to the heat load of consumers. Changing the characteristics of the pump is possible by varying the motor speed.

Let us calculate the efficiency of the boiler circuit with a proportional change in flow rate. At the same time it is necessary to consider that the minimum flow rate of the boiler must be at the $40 \%$ level of the flow rate determined at the nominal power and the difference between outlet and inlet temperature of the heat carrier to be $25^{\circ} \mathrm{C}$ according to the boiler's specification. For example consider the minimum flow limited at $41.1 \mathrm{~m}^{3} / \mathrm{h}$. Thus, if the heat output varies from $1200 \mathrm{~kW}$ to $3000 \mathrm{~kW}$ the flow through the boiler will vary from $41.1 \mathrm{~m} 3 / \mathrm{h}$ to $102.7 \mathrm{~m} 3 / \mathrm{h}$ respectively, and if a heat output is less than $1200 \mathrm{~kW}$, 
the flow through the boiler will be $41.1 \mathrm{~m}^{3} / \mathrm{h}$. Changing of the pump's flow characteristic will be carried out by a frequency converter according to a control algorithm based on the dependence of the flow rate from the motor speed: the boiler room controller calculates the required value of the boiler's heat output based on the parameters of the network circuit heat carrier and the graph of the temperature dependence of the supply pipeline at the heat generating unit output from the outside air temperature.

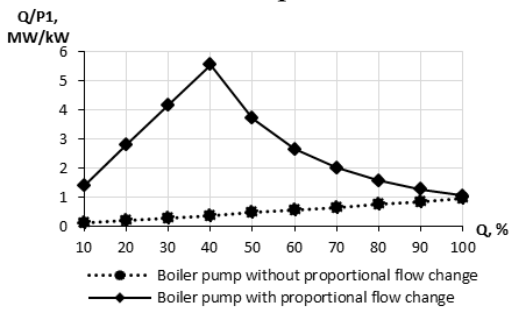

Fig. 4. Consumed electrical power of the boiler pump, depending on the heat load of consumers.

According to the flowmeter installed on the supply line of the boiler circuit and the temperature sensors installed on the supply and return lines of the boiler circuit, the controller calculates the actual value of the boiler's heat output. The difference between the required and actual values should be close to or equal zero. If the difference is less than zero, i.e. the value of the generated heat energy is more than required, the controller sends a signal to reduce the rotational speed of the pump motor. In the case when the difference is greater than zero the frequency converter should receive a signal to increase the frequency. In order to avoid an abrupt change in flow, the control logic must include a proportionalintegral-differentiating (PID) regulator [6,7]. In parallel with this, there should be a smooth regulation of boiler heat output and their cascade connection. The required temperature difference on the sensors installed on the supply and return lines of the boiler circuit is set constant. Otherwise, the pumps will compensate for the low temperature drop by increasing the flow rate, which will lead to over-consumption of electricity. This algorithm for controlling the boiler circuit for a given temperature difference on the supply and return pipelines makes it possible to change the flow rate of the heat carrier in proportion to the change in the heat load of the consumers. All other parameters, the circuit diagram (Fig. 1), the calculation model (Fig. 2) and the equipment are similar to those taken for the first calculated example. As can be seen from the data obtained (Figures 3 and 4, the solid line) the electric power consumption of the pump decreases along with the reduce of the heat output of the circuit throughout the proportionally adjusting range from $40 \%$ to $100 \%$ heat load, which corresponds to a range from $1200 \mathrm{~kW}$ to $3000 \mathrm{~kW}$ (Figure 3). In this case, in comparison to the linear nature of change in the heat load the energy consumption graph in the proportionally adjusting range is an exponential. This is caused by the fact that when the flow rate decreases the pressure loss decreases as well. This decrease is not linear, because the loss of pressure in particular case is a function of the velocity squared and other nonlinear dependences. The simultaneous decrease of both the pump flow rate and the head of pump due to the rotational speed reduction leads to a decrease in the consumed electric energy $[8,9]$. In the range with a constant flow rate (range from $10 \%$ to $40 \%$ (Figure 3 )) there is no change in the electric power consumption. The proportional adjusting of the boiler pump flow rate has made it possible to increase the value of the ratio of the generated heat energy to the consumed electric power of the pump during the heat load decreasing. Thus, the boiler room circuit operation with proportional flow adjusting becomes highly efficient over the entire range of the heat load. Thereby, the energy consumption of the simulated boiler circuit in the boiler room operating at $40 \%$ heat output $(1200 \mathrm{~kW})$ was reduced by 15 times. 
Let us make a calculation of the electricity consumption by the boiler circuit during the heating season for the pump control scheme with a proportional flow rate change and without it. For this purpose there was built a chart of the average daily heat load of consumers in the climatic conditions during the heating season in Tyumen city in 2015. Depending on the average daily outside temperature the average daily heat load was determined by the equation (1):

$$
Q_{\mathrm{O} i}^{\mathrm{day}}=Q_{O} \frac{t_{\mathrm{in}}-t_{i}^{\mathrm{day}}}{t_{\mathrm{in}}-t_{\mathrm{O}}}
$$

where $Q_{\mathrm{O} i}^{\mathrm{day}}$ - average daily heat load of consumers during the particular day of the heating season, $\mathrm{kW} ; Q_{o}$ - calculated load of the heating system for a simulated boiler circuit, assumed to be $3000 \mathrm{~kW}$; $t_{\text {in }}$ calculated internal air temperature, assumed to be $20^{\circ} \mathrm{C}$; $t_{\mathrm{o}-}$ the coldest five-day period temperature, assumed equal to minus $35^{\circ} \mathrm{C} ; t_{i}^{\text {day }}$ - average daily temperature during the $\mathrm{i}$-th day of the heating season, taken as statistical data of average daily temperature during the particular day according to the data of [10].

The electricity consumed per i-th day of the heating season was determined by the equation (2), kWh:

$$
P_{i}=24 \cdot P_{1 i}
$$

where $\mathrm{P}_{1 \mathrm{i}}$ - electric power consumption of boiler pump under average daily heat load of consumers, $\mathrm{kW}$.

Based on the calculation results of the boiler circuit operation modes shown in Figures 3 and 4, approximation equations were found to determine the electric power consumption of the boiler pump with the particular values of the determination coefficient R2.

For the calculating case at a constant electric motor rotation speed of the boiler pump the electrical power can be found by the system of equations (3):

$$
\left\{\begin{array}{l}
P_{1 i}=0.003 G_{\mathrm{y}}+3.456, \text { at } 92.4 \leq G_{\mathrm{y}} \leq 102.7 \text { and } R^{2}=0.99, \\
P_{1 i}=8 \cdot 10^{-8} G_{\mathrm{y}}^{3}-2.6 \cdot 10^{-5} G_{\mathrm{y}}^{2}-6 \cdot 10^{-5} G_{\mathrm{y}}+3.349, \text { at } 0<G_{\mathrm{y}}<92.4 \text { and } R^{2}=0.99
\end{array},\right.
$$

where $G_{y}=$ conditional flow rate of the boiler pump, $\mathrm{m}^{3} / \mathrm{h}$, is found by the equation (4) with the temperature difference $\Delta \mathrm{t}=25^{\circ} \mathrm{C}$ :

$$
G_{\mathrm{y}}=\frac{3.6 \cdot Q_{\mathrm{O} i}^{\mathrm{day}}}{c \cdot \Delta t}
$$

For the calculating case with proportional boiler pump flow adjusting the electrical power can be found by the equation (5):

$$
\left\{\begin{array}{c}
P_{1 i}=0.215, \text { at } 0<G_{\mathrm{y}}<41 \text { and } R^{2}=1, \\
P_{1 i}=2 \cdot 10^{-6} G_{\mathrm{y}}^{3}+8.7 \cdot 10^{-5} G_{\mathrm{y}}^{2}-3 \cdot 10^{-3} G_{\mathrm{y}}+0.036, \text { at } 41<G_{\mathrm{y}} 102.7 \\
\text { and } R^{2}=0.99 .
\end{array}\right.
$$

The electricity consumed during the heating season will be found by the equation (6): 


$$
P=\sum_{i=1}^{220} P_{i}
$$

where, $\mathrm{i}$ - ordinal number of the day during heating season.

Using the equations (1) - (6) there was determined the value of the boiler circuit power consumption for the heating season. For the calculating case of using proportional pump flow adjusting this value was $2332.9 \mathrm{kWh}$, in the case with a constant engine speed of the boiler circuit this value was $17407.4 \mathrm{kWh}$. The obtained results show that using the proportional flow adjusting allowed to reduce the energy consumption of the considered boiler circuit by almost 7.5 times which indicates a high potential for increasing energy efficiency by the proposed method for controlling boiler pumps.

\section{Conclusion}

The analytical evaluation of the proposed method of proportional adjusting of the flow rate has shown a high potential for reducing the energy consumption of heat generating units and becomes the most attractive for investment opportunities.

The example analyzed in this article gives an understanding of the general prospects of the proportional adjusting of the boiler circuit flow rate in boiler rooms. Despite of the high potential for energy saving the use of the proposed method should be based on a feasibility study, because the decrease of the designated boiler room heat output leads to a decrease of the absolute value of the saved resources and a change of the payback period.

The work was supported by the Russian President's grant (Scientific School project 7538.2016.8).

\section{References}

1. Energy strategy of Russia for up to 2035 Available at: http://minenergo.gov.ru/

2. P.A. Khavanov, Heat sources of autonomous heat supply systems: monograph (MGSU, Moscow, 2014)

3. P.A. Khavanov, Bulletin of MGSU, 11, 219 (2012)

4. N.S. Oleinik, Energy saving and water treatment, 6, 92 (2014)

5. S.V. Kolesnikov, Bulletin of the Samara State Technical University, 1, 127 (2014)

6. J. Quevedo, T. Escobet, Digital control: past, present and future of PID control Proceedings of the IFAC Workshop (Terrassa, Spain, 2000)

7. K.J. Astrom, T. Hagglund, The Instrumentation, System, and Automation Society, 460 (2006)

8. V.A. Shabanov, Electrotechnical and Information Complex and Systems, 2, 34 (2013)

9. B. Janusz, Energy, 34, 9 (2009)

10. Daily average air temperature in Tyumen Available at: http://weatherarchive.ru/Temperature/Tyumen/ 